\title{
Evaluation of an Improved General Unknown Screening Procedure Using Liquid- Chromatography-Electrospray-Mass Spectrometry by Comparison with Gas Chromatography and High-Performance Liquid-Chromatography-Diode Array Detection
}

\author{
Franck Saint-Marcoux, Gérard Lachâtre, ${ }^{*}$ and Pierre Marquet \\ Department of Pharmacology and Toxicology, University Hospital, Limoges, France
}

\begin{abstract}
This paper presents an improved, comprehensive liquid chromatography-electrospray-mass spectrometry (LC-ES-MS) general unknown screening (GUS) procedure for drugs and toxic compounds and its comparison with conventional techniques in routine laboratory conditions. Chromatographic separation involved an X-TERRA MS $\mathrm{C}_{18}, 3.5 \mu \mathrm{m}(100 \mathrm{~mm} \times 1 \mathrm{~mm}$ i.d. $)$ column together with a 25-min long gradient of acetonitrile in $\mathrm{pH} 3,2 \mathrm{mM}$ ammonium formate delivered at a $50 \mu \mathrm{l} / \mathrm{min}$ flow rate. Two different in-source collision-induced dissociation voltages were alternated, both in the positive and in the negative ion modes. Reconstructed spectra were then obtained in both polarities by adding up spectra obtained with low and high energy, resulting in spectra presenting a sufficient number of specific fragment ions for unambiguous and fast identification of compounds. Two large mass spectral libraries of drugs and toxic compounds were built and an efficient automated signal processing, library searching and report editing algorithm developed. Using a common, efficient solid-phase extraction procedure, this LC-ES-MS technique was compared to GC-MS and HPLC-DAD GUS procedures for the identification of a priori unknown compounds in 51 serum samples consecutively sent to the laboratory for GUS. The present LC-MS method identified $75 \%$ of the compounds contained in these samples (versus 66\% for GC-MS and 71\% for HPLC-DAD), including $8 \%$ that the other two techniques failed to identify (versus $8 \%$ for GC-MS and $9.5 \%$ for HPLC-DAD). Therefore, it is complementary to GC-MS and/or HPLC-DAD and helps enlarge the range of drugs detected in clinical toxicology. It could be useful as well in forensic toxicology to confirm a positive result, as $38 \%$ of all the compounds were detected by the three techniques and 36\% by two of them. (J Am Soc Mass Spectrom 2003, 14, 14-22) (C) 2003 American Society for Mass Spectrometry
\end{abstract}

$\mathrm{W}$ hat clinical and forensic toxicologists expect from a general unknown screening (GUS) procedure is the unambiguous identification of the xenobiotics involved in intoxication cases, even when they have no clues to guide the search. Automated immunoassays generally represent a first approach and provide a result in a few minutes, but these

Published online November 28, 2002

Address reprint requests to Dr. P. Marquet, Service de Pharmacologie et Toxicologie, CHU Dupuytren, 87042 Limoges cedex, France. E-mail: marquet@unilim.fr

*Also at the Laboratory of Toxicology, Faculty of Pharmacy, Limoges, France. techniques allow, for most of them, only a class-diagnostic, notwithstanding the limited number of classes available.

On the contrary, chromatographic techniques coupled to specific detectors such as mass spectrometers or UV-diode array detectors cover a very large panel of relevant compounds [1-4]. Nevertheless, the limited specificity of UV spectra (since several compounds can have similar UV-spectra), their variability as a function of $\mathrm{pH}$ and the fact that a lot of compounds present poor or no UV absorbance, make HPLC-UV-DAD not very specific, reliable, nor universal. Thus, very few UV spectrum libraries are commercially available. On the 
contrary, due to its widespread availability and its high specificity, gas chromatography/mass spectrometry (GCMS) is considered as being the gold standard technique for general unknown screening in toxicology. It is based on electron ionization (EI) with standard conditions (70 $\mathrm{eV)}$ for which very large EI-mass spectra libraries exist [1, 2]. However, due to the gas phase properties, GC-MS presents some weak points. It requires time-consuming extraction procedures and sometimes cleavage of conjugates prior to extraction. Drugs or metabolites can be detected in their native form only if they are thermally stable, volatile, and mildly or nonpolar. Furthermore, derivatization and artifact formation significantly complicates the identification process [5].

For these reasons, liquid chromatography-mass spectrometry (LC-MS) which uses both an almost universal separation process and the most specific and sensitive type of detector, is a promising, alternative approach to GC-MS and HPLC-DAD [5, 6]. Though electrospray ionization sources entail a soft ionization process, almost as much fragmentation can be obtained using in-source collision induced dissociation (CID) as with CID in the collision cell of a MS-MS system.

Recently the first complete, standardized, automated, and routinely applicable GUS procedure for drugs in serum based on LC-ES-MS, using in-source CID at various orifice voltages, both in the positive and negative ionization modes [7-9] was reported. Using this procedure, two CID-MS spectra libraries were built: One library comprising of about 1100 reconstructed mass spectra in the positive mode, and another of about 500 mass spectra in the negative mode. Each of these so-called reconstructed spectra was obtained by adding up one spectrum obtained at low $(20 \mathrm{~V})$ and one obtained at high $(80 \mathrm{~V})$ fragmentation voltage, and thus presented, in addition to the molecular or protonated ion, a sufficient number of fragment ions to allow efficient and specific compound identification.

To the best of our knowledge, no other such comprehensive LC-ES-MS screening procedure has been proposed up till now, although an increasing number of papers concerning the application of LC-MS to forensic and clinical toxicology have been published in the last two years [10-17]. However, the analytical time of this procedure was still too long $(1 \mathrm{~h})$ to be used routinely in a clinical toxicological laboratory.

This paper presents an improved LC-ES-MS general unknown screening procedure and an evaluation of the performance of this technique by comparison with that of classical GC-MS and HPLC-DAD GUS procedures, using a common efficient extraction procedure for the three techniques.

\section{Materials and Methods}

\section{Standards and Reagents}

Organic solvents and reagents were all of analytical grade. Acetonitrile and methanol were obtained from
Carlo Erba (Milan, Italy), formic acid, ammonium formate and potassium phosphate from Sigma (St. Louis, $\mathrm{MO}$ ). Deionized water was prepared on a MilliQ laboratory plant (Millipore, Bedford, MA). Glafenin was purchased from Sigma (St. Louis, MO). Quality control serum samples (Therapeutic Drug Monitoring Control Level 1) were obtained from BIO-RAD (Ivry-sur-Seine, France). Oasis MCX extraction cartridges were purchased from Waters (St. Quentin-en-Yvelines, France) and prepacked NT1 Extrelut from Merck KgaA (Darmstadt, Germany).

\section{Sample Preparation Procedures}

Reference solid-phase extraction prior to the GC-MS screening procedure. One $\mathrm{mL}$ of serum was acidified by addition of $1 \mathrm{~mL} 0.1 \mathrm{~N} \mathrm{HCl}$ and deposited on a prepacked NT1 Extrelut column (diatomaceous earth phase). $1 \mathrm{~mL}$ of serum was alkalized by addition of 1 $\mathrm{mL}$ pH 9.7 sodium carbonate buffer, then loaded on another prepacked Extrelut NT1 column. These two samples were extracted by addition of $10 \mathrm{~mL}$ dichloromethane to each cartridge. The two extracts were then mixed, evaporated to dryness (nitrogen gas at $70{ }^{\circ} \mathrm{C}$ ) and finally redissolved in $100 \mu \mathrm{L}$ of $40 \mathrm{mg} / \mathrm{L}$ protryptiline (I.S.) methanolic solution.

Reference liquid-liquid extraction prior to the HPLC-DAD screening procedure. A mixture of $0.5 \mathrm{~mL}$ serum, $0.5 \mathrm{~mL}$ $\mathrm{pH} 9.5 \mathrm{NH}_{4} \mathrm{Cl} /$ deionized water (30:70, vol/vol) and 25 $\mu \mathrm{L}$ of a methylclonazepam (I.S.) solution at $50 \mathrm{mg} / \mathrm{L}$ was vortex-mixed and extracted by addition of $8 \mathrm{~mL}$ of $\mathrm{CH}_{3} \mathrm{Cl} / 2$-propanol/heptane (60:14:26 vol/vol/vol). The organic phase was evaporated to dryness at $37^{\circ} \mathrm{C}$ and the residue dissolved in $50 \mu \mathrm{L}$ methanol/water (50:50 vol/vol).

Evaluation of the common solid-phase extraction for the three GUS techniques. A common procedure for the isolation of compounds from biologic matrices prior to LC-MS, GC-MS, and HPLC-DAD GUS procedures was developed. One $\mathrm{mL}$ of serum was deposited on an Oasis MCX, mixed-mode phase extraction cartridge containing both hydrophobic polymers and sulfonic acid (cation exchange) functional groups, previously conditioned with $1 \mathrm{~mL}$ methanol and $1 \mathrm{~mL}$ deionized water. After rinsing the cartridge with $1 \mathrm{~mL} 0.1 \mathrm{~N}$ hydrochloric acid, elution was performed with $1 \mathrm{~mL}$ of a methanolammonium hydroxide solution (25\%) (98:2 vol/vol) mixture. The extract was divided into three parts that were evaporated to dryness under a nitrogen stream at room temperature. For the LC-MS procedure, the dry extract was dissolved in $100 \mu \mathrm{l}$ of a deproteinated serum/acetonitrile (50:50 vol/vol) mixture, obtained by adding $100 \mu \mathrm{L}$ glafenin (I.S.) working solution in acetonitrile to $100 \mu \mathrm{L}$ serum, followed by vortex-mixing and centrifugation (some deproteinated serum was thus added to the dry extract with the aim of increasing the recovery of the most hydrophilic drugs). This addition 
of deproteinated serum was not applied to the two other techniques as it resulted in a dramatic increase in background noise on UV and E.I. spectra. For GC-MS, the dry extract was reconstituted with $100 \mu \mathrm{L}$ of 40 $\mathrm{mg} / \mathrm{L}$ protriptyline (I.S.) methanolic solution. For HPLC-DAD, the dry extract was reconstituted in methanol/water (50:50 vol/vol) containing methylclonazepam (I.S.) at $50 \mathrm{mg} / \mathrm{L}$.

In order to validate for GC-MS and HPLC-DAD this SPE procedure initially developed for LC-MS, a study was carried out using 51 serum samples sent to the lab by adult and pediatric emergency departments for suspected intoxication or acute poisoning cases. Both the usual reference extraction methods for GC-MS and HPLC$\mathrm{DAD}$ and the present SPE procedure were performed in parallel. The results obtained by GC-MS and HPLC-DAD with the candidate SPE were compared to those obtained with the respective reference extraction methods.

\section{LC-MS Method}

The chromatographic system consisted of a Series 200LC micro-flow rate, high pressure gradient pumping system, and a Series 200 Auto-sampler (PerkinElmer Instruments, Les Ulis, France) including a Rheodyne model 7725 injection valve equipped with a $5 \mu \mathrm{l}$ internal loop. Chromatographic separation was performed on a X TERRA MS $C_{18} 3.5 \mu \mathrm{m}(100 \mathrm{~mm} \times 1 \mathrm{~mm}$ i.d.) column (Waters, St. Quentin-en-Yveline, France), using a linear gradient of acetonitrile (ACN) in $2 \mathrm{mM}$, pH 3.0 ammonium formate, as mobile phase (constant flow-rate $50 \mu \mathrm{L} / \mathrm{min}$ ), programmed as follows: $0-1$ $\mathrm{min}, 5 \% \mathrm{ACN} ; 1-20 \mathrm{~min}, 10$ to $90 \% \mathrm{ACN} ; 21-22 \mathrm{~min}$, 90\% ACN; 22-22.5 min, decrease from 90 to 5\% ACN; 22.5-25.5 min, column equilibration with 5\% ACN.

Mass spectrometric analyses were conducted using an API 100 single quadrupole instrument (Applied Biosystem-Sciex, Concord, Canada), equipped with a pneumatically assisted electrospray (Ionspray) ionization source. The whole system was controlled using a G3 Power Macintosh computer equipped with LC2Tune, MultiView 1.4 and Sample Control 1.1 software (Applied Biosystem-Sciex). Ionization in the Ionspray source was performed in the positive and negative modes, scanning masses from $\mathrm{m} / \mathrm{z} 100$ to 1100 , with a $0.2 \mathrm{u}$ step size. In the positive mode, ionization voltage was $+5500 \mathrm{~V}, \mathrm{Q}_{0}+10 \mathrm{~V}$, ring $+275 \mathrm{~V}$, orifice (fragmentation) voltages $+20 \mathrm{~V}$ and $+80 \mathrm{~V}$; in the negative mode, ionization voltage was $-4500 \mathrm{~V}, \mathrm{Q}_{0}-10 \mathrm{~V}$, ring $-250 \mathrm{~V}$, orifice voltages $-20 \mathrm{~V}$ and $-80 \mathrm{~V}$. The influence of the fragmentation energy and ion-source geometrical configuration on ionization and fragmentation efficiency were shown in previous studies $[8,9]$, and the optimal distance between the ionization needle and the mass spectrometer entrance orifice found to be approximately $6 \mathrm{~mm}$. However, before each experiment, this distance was finely adjusted to obtain a reference fragmentation spectrum of glafenin (test compound) and to provide a good reproducibility of compound fragmentation.

These four ionization conditions resulted in four chromatograms corresponding to each polarity and fragmentation voltage value. Positive and negative reconstructed spectra were obtained by adding, in the centroid mode (merge distance $1 \mathrm{u}$, minimum width $1 \mathrm{u}$ ) spectra at $+20 \mathrm{~V}$ and $+80 \mathrm{~V}$ on the one hand and spectra at $-20 \mathrm{~V}$ and $-80 \mathrm{~V}$ on the other. These four acquisition conditions were looped. In order to obtain a sufficient number of points for each chromatographic peak and so enable their efficient detection and integration, the shortest convenient dwell time was found to be $0.06 \mathrm{~ms}$ (actual count time for each step in the mass range). Below this value, a loss of signal intensity was noted. So each scan in the $100-1100 \mathrm{u}$ range was $1.21 \mathrm{~s}$ long. The "polarityswitching time", corresponding to the time required by the instrument for switching from one ionization polarity to the other, was set at $0.9 \mathrm{~ms}$. Attempts to reduce this value further resulted in a dramatic loss of signal intensity. Finally, the 30 min-long chromatogram corresponded to 589 iterations of a $3.055 \mathrm{~s}$ long loop.

\section{GC-MS and HPLC-DAD Methods}

Briefly, GC-MS was performed using a model 5890 gas chromatograph (Hewlett-Packard, Les Ulis, France) equipped with a glass needle injector and a PTE, $30 \mathrm{~m} \times 0.32 \mathrm{~mm}$ i.d., $0.25 \mu \mathrm{m}$ film thickness capillary column (Sigma, St. Quentin Fallavier, France). Oven temperature was programmed from 110 to $220{ }^{\circ} \mathrm{C}$ at $20^{\circ} \mathrm{C} / \mathrm{min}$, from 220 to $260{ }^{\circ} \mathrm{C}$ at $2{ }^{\circ} \mathrm{C} / \mathrm{min}$, up to $280{ }^{\circ} \mathrm{C}$ at $10^{\circ} \mathrm{C} / \mathrm{min}$, maintained for $15 \mathrm{~min}$. The injector and interface temperatures were 270 and $280{ }^{\circ} \mathrm{C}$, respectively. A MSD 5972 mass spectrometer (Hewlett-Packard, Les Ulis, France) was used as a detector, operated in the electron ionization mode at $70 \mathrm{eV}$, scanning masses from 440 to $510 \mathrm{u}$ at a speed of 2.5 scans/s. An in-house as well as two commercial electronic libraries of EI mass spectra (PMW-Tox2 [1] and Wiley 7N [18]) were used for compound identification.

HPLC-DAD was performed using a LC10A high pressure binary gradient pumping system (Shimadzu, Duisburg, Germany) a Nucleosil C18, $5 \mu \mathrm{m}(150 \times 4.6$ $\mathrm{mm}$ i.d.) stainless steel column together with a gradient of $\mathrm{ACN}$ in $\mathrm{pH} 2.6,25 \mathrm{mM}$ potassium phosphate buffer (15\% ACN for $2 \mathrm{~min}$, increased linearly to $75 \%$ in 40 $\mathrm{min}$, then to $90 \%$ in $3 \mathrm{~min}$, maintained for $3 \mathrm{~min}$ ) delivered at a constant flow rate of $1.3 \mathrm{~mL} / \mathrm{min}$. Detection was performed using a Shimadzu SPDM 10A diode array spectrophotometer, scanning the 200-400 nm wavelength range with a $1 \mathrm{~nm}$ resolution. An in-house library of over 1500 UV spectra of drugs, toxic compounds and metabolites was used for compound identification. 


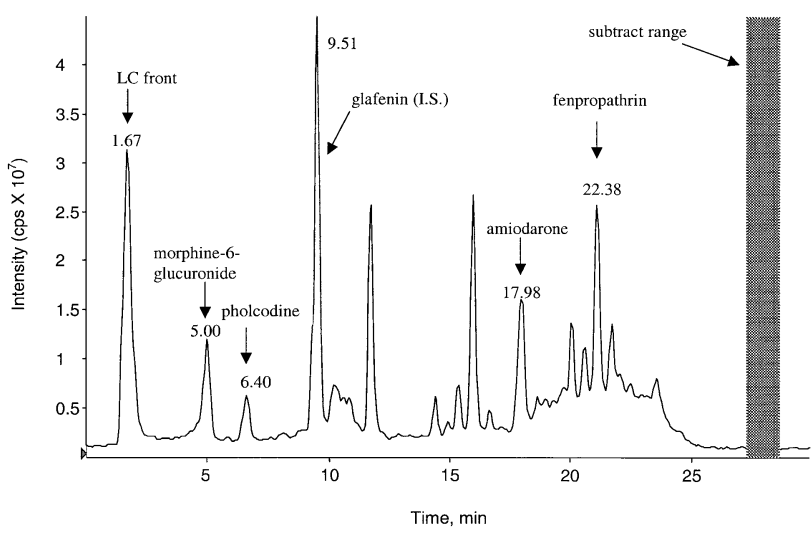

Figure 1. Total Ion Current (TIC) chromatogram obtained from a blank serum spiked with morphine-6-glucuronide, pholcodine, amiodarone, and fenpropathrin (insecticide) at $10 \mathrm{mg} / \mathrm{l}$, in the positive single full-scan (100 to $1100 \mathrm{u}$ ) mode.

\section{Comparison Between LC-MS, GC-MS and HPLC- DAD GUS Procedures}

Each of the 51 serum samples were extracted following the common, validated SPE procedure described above then analyzed using GC-MS, HPLC-DAD and LC-MS within a $48 \mathrm{~h}$ period. The qualitative results (number and nature of compounds detected) obtained with the three different analytical procedures were used to evaluate their respective performance, considering as reference the combination of these three techniques (i.e., the compounds supposed to be present in each clinical sample were those found by at least one of these techniques).

\section{Results and Discussion}

What can be expected from a general unknown screening procedure is the unambiguous identification of a very large range of drugs, poisons, pesticides, and metabolites. It requires a good sensitivity and a high specificity. However, an effective nontarget analysis should also be as fast as possible, especially when the need for accurate information is urgent. The present LC-ES-MS technique allows highly polar to highly nonpolar compounds to be separated using a $30 \mathrm{~min}$ chromatographic run. As an example, a chromatogram is presented in Figure 1, corresponding to a blank serum sample obtained from a healthy volunteer and spiked at $10 \mathrm{mg} / \mathrm{L}$ with the highly polar morphine-6glucuronide, the mildly polar pholcodine, the highly lipophilic amiodarone, and fenpropathrin (an insecticide), with glafenin as internal standard. The LC-front peak was found at $1.7 \mathrm{~min}$ whereas morphine-6-glucuronide was eluted at about $5 \mathrm{~min}$. Amiodarone and fenpropathrin were eluted in $18 \mathrm{~min}$ and $22.5 \mathrm{~min}$ respectively, compared to about $45 \mathrm{~min}$ under the previously published chromatographic conditions [9].

Electrospray ionization sources entail a soft ionization process. So, spectra obtained are known to be poorly informative since very few or no fragment ions are produced by this process. The best solution found to obtain rich, specific, and informative mass spectra was to create "reconstructed" spectra by adding up two spectra acquired with low and high fragmentation energies, respectively, which in most cases contained both the protonated molecule $( \pm 20 \mathrm{~V})$ and several fragment ions $( \pm 80 \mathrm{~V})$.

A general unknown screening procedure must be able to detect and identify basic, acidic, or neutral unexpected compounds within a large range of lipid solubility. Thus, it requires a nonclass-specific extraction procedure able to isolate the widest range of relevant molecules from biological matrices. Such procedures may involve a single liquid-liquid extraction, two liquid-liquid extractions in parallel (one for acidic and one for basic compounds) [11, 12], solid-phase extraction with classical hydrophobic $\mathrm{C} 18$ bonded phase [13], or mixed-mode phase SPE [13-16]. The Oasis MCX extraction cartridges used for the present study involve both reverse phase retention on a polymeric support and strong cation exchange properties, thus increasing the polarity range of extracted compounds. However, to increase the recovery of hydrophilic compounds, generally poorly retained on SPE cartridges, some serum deproteinated with acetonitrile was added to the dry extract (instead of dissolving it with ammonium formate and acetonitrile). The protein precipitation step by dilution $1 / 2$ in acetonitrile resulted in a theoretical $1 / 2$ dilution of hydrophilic compounds in the supernatant, but the toxic levels of hydrophilic compounds are generally much higher than those of lipid soluble drugs.

A first hint of the efficiency of the present comprehensive LC-MS GUS method, including automated signal processing and library searching, was given by the analysis of an extract of a commercial internal quality control (IQC) for therapeutic drug monitoring (TDM Control Level 1, BIO-RAD, Ivry-sur-Seine, France). This IQC consists of a pool of blank serum spiked with different drugs at known, low therapeutic concentrations (i.e., lowest levels on a scale of three) [19] and is used to check the accuracy of the analytical techniques employed for these molecules. Thirteen of the 27 drugs and metabolites contained at these low therapeutic levels were identified (see Table 1 and Figure 2), including acidic (e.g., acetaminophen, phenobarbital, and salicylic acid) as well as basic (e.g., amitriptyline, phenytoin) drugs. Acidic drugs with a low pKa may not show up in the positive ionization mode. For example, salicylic acid present in the IQC sample at a concentration of $260 \mathrm{mg} / \mathrm{L}$ was only detected in the negative ionization mode, at a retention time of $10.9 \mathrm{~min}$. Thus, libraries of negative spectra are indispensable for acidic compounds that may not be detected in the positive ionization mode and are hardly amenable to GC-MS without derivatization. In the best cases, positive and negative spectra can both be identified in the respective libraries and confirm each other. They can also be useful 
Table 1. Efficacy of the LC-MS procedure for detecting and identifying compounds in a commercial quality control for therapeutic drug monitoring (Therapeutic Drug Monitoring Control Level 1, BIO RAD, Ivry-sur-Seine, France)

\begin{tabular}{|c|c|c|c|c|c|c|c|}
\hline Compound & $\begin{array}{c}\text { Molecular } \\
\text { weight }\end{array}$ & $\begin{array}{l}\text { Retention } \\
\text { time min }\end{array}$ & $\begin{array}{c}\text { lons with } \\
\text { positive } \\
\text { ionization } \mathrm{m} / \mathrm{z} \\
\end{array}$ & $\begin{array}{c}\text { lons with the } \\
\text { negative } \\
\text { ionization } \\
\mathrm{m} / \mathrm{z}\end{array}$ & $\begin{array}{c}\text { Concentration } \\
\text { level } \mathrm{mg} / \mathrm{L}\end{array}$ & $\begin{array}{c}\text { Therapeutic } \\
\text { plasma } \\
\text { concentration } \\
\text { (less than) } \\
\text { mg/L (19) }\end{array}$ & $\begin{array}{c}\text { Plasma } \\
\text { concentration } \\
\text { leading to serious } \\
\text { toxicity } \mathrm{mg} / \mathrm{L}(19) \\
\end{array}$ \\
\hline Procainamide & 235.79 & 6.18 & $\begin{array}{c}236.8 ; 163 ; \\
120\end{array}$ & I & 2.1 & 8 & 12 \\
\hline Acetaminophen & 151.20 & 6.26 & $152 ; 110$ & 150 & 13 & 30 & 200 \\
\hline Theophylline & 180.20 & 7.64 & $181 ; 124$ & $179 ; 164 ; 137$ & 4.8 & 20 & 40 \\
\hline Quinidine & 324.43 & 8.19 & $\begin{array}{c}325.6 ; 253 ; \\
172\end{array}$ & I & 1.3 & 5 & 8 \\
\hline Disopyramide & 339.47 & 8.84 & $\begin{array}{c}341.4 ; 239 \\
195\end{array}$ & l & 0.8 & 5 & 8 \\
\hline Primidone & 218.26 & 9.11 & $\begin{array}{c}219.2 ; 162 ; \\
199\end{array}$ & l & 2.9 & 12 & 40 \\
\hline Salicylic acid & 138.12 & 11.70 & l & 137.4 & 260 & 300 & 400 \\
\hline Phenobarbital & 319.89 & 11.22 & $271 ; 250$ & $232 ; 306$ & 9.4 & 40 & 100 \\
\hline Chloramphenicol & 323.14 & 11.35 & $324 ; 305 ; 275$ & $321 ; 257 ; 194$ & 5.8 & 25 & 40 \\
\hline Imipramine & 280.40 & 12.30 & $\begin{array}{c}281.2 ; 208 ; \\
193\end{array}$ & l & 0.122 & 0.3 & 1 \\
\hline Amitriptyline & 277.39 & 12.60 & $\begin{array}{c}\text { 279.3; 218; } \\
191\end{array}$ & I & 0.084 & 0.3 & 1 \\
\hline Phenytoin & 252.26 & 12.92 & $\begin{array}{c}\text { 253.2; 225; } \\
182\end{array}$ & $251 ; 199$ & 7.2 & 20 & 40 \\
\hline Carbamazepine & 236.26 & 13.10 & $\begin{array}{c}237.1 ; 194 ; \\
179\end{array}$ & l & 2.8 & 12 & 30 \\
\hline
\end{tabular}

to determine the molecular weight of a compound not recorded in the libraries.

On the raw, total-ion current (TIC) chromatogram shown in Figure 2, some peaks appear with very low intensity, owing to their low concentration but also to the high background noise obtained in the scan mode. However, this limitation was overcome by using the previously described "enhance" function available on the Mac version of the software [9] that allowed the detection of closely eluted or low-intensity peaks (e.g., peak at $11.7 \mathrm{~min}$ in Figure 2).

Finally, the wide range of molecules positively iden-

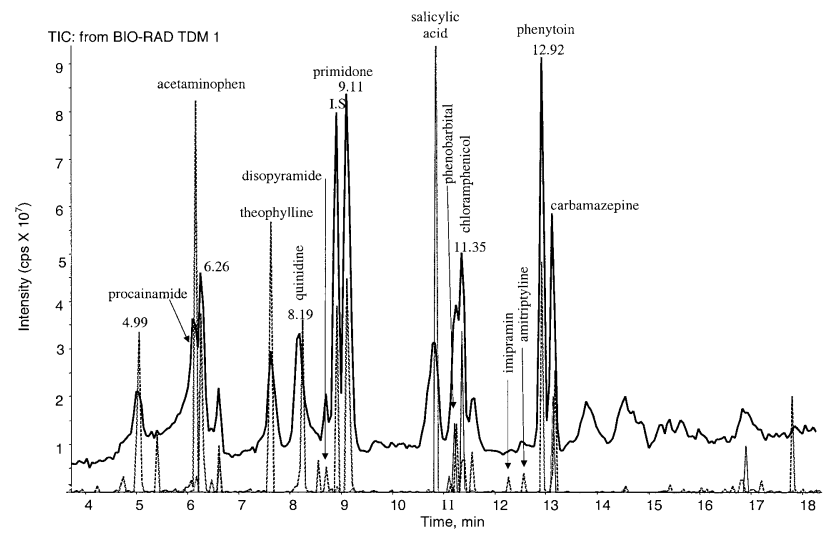

Figure 2. Zoomed view of a LC-MS total ion chromatogram obtained from an extract of a commercial quality control for therapeutic drug monitoring (Bio-Rad, TDM 1). Bold line: Raw TIC chromatogram. Doted line: Enhanced, positive ion TIC chromatogram. Thin line: Enhanced, negative ion TIC chromatogram. tified at low therapeutic serum concentration in this sample is a first argument in favor of the efficacy of this comprehensive method. However, amikacin, cyclosporine, digoxin, ethosuximide, flecainid, gentamycin, lidocaine, methotrexate, netilmicin, tobramycin, caffeine, desipramine, nortriptylin, and propranolol were not identified at these low concentrations.

\section{Comparison Between LC-ES-MS, HPLC-DAD and GC-MS Screening Procedures}

Validation of the common solid-phase extraction procedure. Fifty-one serum samples sent to our lab in a clinical or forensic context were analyzed in parallel with the reference extraction methods (LLE in alkaline conditions for HPLC-DAD and double acidic/basic extraction on NT1 Extrelut for GC-MS) and with the SPE procedure using Oasis MCX cartridges. Overall, 78 hits corresponding to 39 different compounds of toxicological interest were found. For each serum sample analyzed, the results were identical with the tested SPE procedure and the reference ones, except in two cases: Bromazepam and midazolam were not detected by the tested SPE in one sample each. However, these two particularly unstable benzodiazepines might have been degraded because of the delay (which could reach $48 \mathrm{~h}$ ) between the first routine analysis using the usual reference extraction procedure and the second assay involving the new SPE method. Moreover, they were generally correctly identified in other samples using the candidate SPE (Table 2). Another explanation might be 
Table 2. Therapeutic drugs and toxic compounds detected in 51 serum samples using HPLC-DAD and GC-MS following a common SPE method as compared with the reference extraction techniques

\begin{tabular}{|c|c|c|c|c|}
\hline \multirow[b]{2}{*}{ Sample } & \multicolumn{2}{|c|}{ GC-MS } & \multicolumn{2}{|c|}{ HPLC-DAD } \\
\hline & Reference LLE & Common SPE & Reference LLE & Common SPE \\
\hline 1 & Acetaminophen & Acetaminophen & Acetaminophen & Acetaminophen \\
\hline 2 & Zolpidem & Zolpidem & Zolpidem & Zolpidem \\
\hline 3 & Mianserine, methadone & Mianserine, methadone & $\begin{array}{l}\text { Citalopram, methadone, } \\
\text { EDDP }\end{array}$ & Citalopram, methadone, EDDP \\
\hline 4 & $\begin{array}{l}\text { Acetaminophen, valproic } \\
\text { acid, phenobarbitone, } \\
\text { phenytoin }\end{array}$ & $\begin{array}{l}\text { Acetaminophen, valproic } \\
\text { acid, phenobarbitone, } \\
\text { phenytoin }\end{array}$ & Acetaminophen & Acetaminophen \\
\hline 5 & ND & ND & ND & ND \\
\hline 6 & $\begin{array}{l}\text { Meprobamate, } \\
\text { acetaminophen, } \\
\text { zolpidem }\end{array}$ & $\begin{array}{l}\text { Meprobamate, } \\
\text { acetaminophen, zolpidem }\end{array}$ & $\begin{array}{l}\text { Bromazepam, } \\
\text { acetaminophen, zolpidem }\end{array}$ & $\begin{array}{l}\text { Bromazepam, acetaminophen, } \\
\text { zolpidem }\end{array}$ \\
\hline 7 & Acetaminophen & Acetaminophen & Acetaminophen & Acetaminophen \\
\hline 8 & ND & ND & ND & ND \\
\hline 9 & ND & ND & Cetirizine, salicylic acid & Cetirizine, salicylic acid \\
\hline 10 & Acetaminophen & Acetaminophen & Acetaminophen & Acetaminophen \\
\hline 11 & ND & ND & Clorazepate dipotassium & Clorazepate dipotassium \\
\hline 12 & ND & ND & ND & ND \\
\hline 13 & ND & ND & Clorazepate dipotassium & Clorazepate dipotassium \\
\hline 14 & Acetaminophen & Acetaminophen & $\begin{array}{l}\text { Norldiazepam, } \\
\text { acetaminophen }\end{array}$ & Nordiazepam, acetaminophen \\
\hline 15 & Bromazepam & ND & Bromazepam & ND \\
\hline 16 & Ibuprofen, niflumic acid & Ibuprofen, niflumic acid & Niflumic acid, indomethacin & Niflumic acid, indomethacin \\
\hline 17 & $\begin{array}{l}\text { Phenobarbitone, } 7 \\
\text { aminoflunitrazepam }\end{array}$ & $\begin{array}{l}\text { Phenobarbitone, 7- } \\
\text { aminoflunitrazepam }\end{array}$ & $\begin{array}{l}\text { Phenobarbitone, } 7- \\
\text { aminoflunitrazepam }\end{array}$ & $\begin{array}{l}\text { Phenobarbitone, 7- } \\
\text { aminoflunitrazepam }\end{array}$ \\
\hline 18 & ND & ND & Cefoxitin & Cefoxitin \\
\hline 19 & $\begin{array}{l}\text { Acetaminophen, } \\
\text { dextropropoxyphen, } \\
\text { diazepam, nordiazepam }\end{array}$ & $\begin{array}{l}\text { Acetaminophen, } \\
\text { dextropropoxyphen, } \\
\text { diazepam, nordiazepam }\end{array}$ & $\begin{array}{l}\text { Acetaminophen, } \\
\text { dextropropoxyphen, } \\
\text { diazepam, nordiazepam }\end{array}$ & $\begin{array}{l}\text { Acetaminophen, } \\
\text { dextropropoxyphen, } \\
\text { diazepam, nordiazepam }\end{array}$ \\
\hline 20 & Midazolam & Midazolam & Midazolam & Midazolam \\
\hline 21 & Acetaminophen & Acetaminophen & Acetaminophen & Acetaminophen \\
\hline 22 & ND & ND & ND & ND \\
\hline 23 & $\begin{array}{l}\text { Nordiazepam, } \\
\text { phenobarbitone }\end{array}$ & $\begin{array}{l}\text { Nordiazepam, } \\
\text { phenobarbitone }\end{array}$ & Nordiazepam & Nordiazepam \\
\hline 24 & Cyamemazine & Cyamemazine & Cyamemazine, oxazepam & Cyamemazine, oxazepam \\
\hline 25 & ND & ND & ND & ND \\
\hline 26 & ND & ND & Oxazepam & Oxazepam \\
\hline 27 & Nordiazepam & Nordiazepam & Nordiazepam & Nordiazepam \\
\hline 28 & Midazolam, lidocain & Midazolam, lidocain & Midazolam & Midazolam \\
\hline 29 & Levomepromazine & Levomepromazine & ND & ND \\
\hline 30 & ND & ND & Propafenone & Propafenone \\
\hline 31 & ND & ND & Clorazepate dipotassium & Clorazepate dipotassium \\
\hline 32 & Acetaminophen & Acetaminophen & $\begin{array}{l}\text { Acetaminophen, } \\
\text { furosemide, midazolam }\end{array}$ & Acetaminophen, furosemide \\
\hline 33 & ND & ND & Piroxicam & Piroxicam \\
\hline 34 & Nordiazepam & Nordiazepam & Nordiazepam & Nordiazepam \\
\hline 35 & ND & ND & Flecainide & Flecainide \\
\hline 36 & Acetaminophen & Acetaminophen & Acetaminophen & Acetaminophen \\
\hline 37 & Clonazepam & Clonazepam & Clonazepam & Clonazepam \\
\hline 38 & $\begin{array}{l}\text { Acetaminophen, } \\
\text { amitriptyline }\end{array}$ & $\begin{array}{l}\text { Acetaminophen, } \\
\text { amitriptyline }\end{array}$ & $\begin{array}{l}\text { Acetaminophen, } \\
\text { amitriptyline }\end{array}$ & Acetaminophen, amitriptyline \\
\hline 39 & Lidocain & Lidocain & ND & ND \\
\hline 40 & Hydroxychloroquine & Hydroxychloroquine & ND & ND \\
\hline 41 & Fluoxetine & Fluoxetine & Fluoxetine, piroxicam & Fluoxetine, piroxicam \\
\hline 42 & $\begin{array}{l}\text { Phenobarbitone, } \\
\text { mianserin }\end{array}$ & Phenobarbitone, mianserin & Mianserin & Mianserin \\
\hline 43 & Nordiazepam & Nordiazepam & Nordiazepam, oxazepam & Nordiazepam, oxazepam \\
\hline 44 & ND & ND & Clorazepate dipotassium & Clorazepate dipotassium \\
\hline 45 & $\begin{array}{l}\text { Acetaminophen, } \\
\text { phenobarbitone }\end{array}$ & $\begin{array}{l}\text { Acetaminophen, } \\
\text { phenobarbitone }\end{array}$ & Acetaminophen & Acetaminophen \\
\hline 46 & ND & ND & Citalopram & Citalopram \\
\hline
\end{tabular}


Table 2. Continued

\begin{tabular}{|c|c|c|c|c|}
\hline \multirow[b]{2}{*}{ Sample } & \multicolumn{2}{|c|}{ GC-MS } & \multicolumn{2}{|c|}{ HPLC-DAD } \\
\hline & Reference LLE & Common SPE & Reference LLE & Common SPE \\
\hline 47 & ND & ND & Moclobemide & Moclobemide \\
\hline 48 & ND & ND & Clobazam & Clobazam \\
\hline 49 & $\begin{array}{l}\text { Phenobarbitone, } \\
\text { carbamazepine }\end{array}$ & $\begin{array}{l}\text { Phenobarbitone, } \\
\text { carbamazepine }\end{array}$ & Carbamazepine & Carbamazepine \\
\hline 50 & ND & ND & ND & ND \\
\hline 51 & Ethosuximide & Ethosuximide & Chloramphenicol & Chloramphenicol \\
\hline
\end{tabular}

that of the difference in sample volume for the two extraction procedures: the classical LLE prior to HPLCDAD requires $2 \mathrm{~mL}$ of serum, whereas the tested SPE uses only $1 \mathrm{~mL}$ for the three techniques (extract divided into three equal parts before evaporation), i.e., $1 / 3 \mathrm{~mL}$ for each. However, it was not possible to confirm that these benzodiazepines were at a low concentration in these particular samples, as our GUS procedures are not quantitative.

The discrepancies between the different chromatographic/detection techniques are addressed in the following section, considering only the case where a common extraction method is used.

Study of 51 serum samples from routine clinical toxicology activity. The three methods were compared for the analysis of the same 51 serum samples as above, considering only the common, nonselective solid-phase extraction method developed for the present study. Eighty-four hits (corresponding to 46 different compounds) were detected at least by one of these three techniques. The results are summarized in Figure 3. Sixty-three hits $(75 \%)$ were obtained with LC-ES-MS, compared to $55(65.5 \%)$ with GC-MS, and $60(71.4 \%)$ with HPLC-DAD. Of note, it corresponds to the detection of 39 different compounds by LC-MS compared to 27 and 32 by GC-MS and HPLC-DAD, respectively. About $8 \%$ of all hits were obtained by LC-MS alone, i.e., exactly the same percentage as by GC-MS, compared to $9.5 \%$ by HPLC-DAD. Therefore, none of these three

\begin{tabular}{|c|c|c|c|c|c|}
\hline & & $\begin{array}{l}\text { chloralose, methotrexate, } \\
\text { mycophenolic acid, } \\
\text { noscapine, nitrendipine, } \\
\text { simvastatine, tianeptine }\end{array}$ & $8.3 \%$ & $\begin{array}{l}\text { LC-MS } \\
75.0 \%\end{array}$ & \\
\hline $\begin{array}{l}\text { GC-MS } \\
65.5 \%\end{array}$ & \multirow{2}{*}{$\begin{array}{l}11.9 \% \\
\text { ibuprofen, } \\
\text { levomeromazine, } \\
\text { meprobamate, } \\
\text { mianserin, } \\
\text { phenobarbital (5), } \\
\text { phenytoin }\end{array}$} & \multirow{2}{*}{ 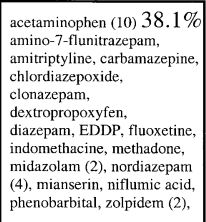 } & \multirow{2}{*}{\multicolumn{2}{|c|}{$\begin{array}{l}\text { cetirizine, } \\
\text { citalopram (2) } \\
\text { chloramphenicol, } \\
\text { chlordiazepoxide (2), } \\
\text { clobazam, } \\
\text { flecainide, } \\
\text { furosemide, } \\
\text { oxazzepam, } \\
\text { moclobemide, } \\
\text { piroxicam (2), } \\
\text { quinidine }\end{array}$}} & $\begin{array}{c}\text { HPLC-DAD } \\
71.4 \%\end{array}$ \\
\hline $8.3 \%$ & & & & & $\begin{array}{l}9.5 \% \\
\text { bromazepam (2), } \\
\text { cefoxitin, } \\
\text { chlordiazepoxide, } \\
\text { nordiazepam, } \\
\text { oxazenam, }\end{array}$ \\
\hline $\begin{array}{l}\text { ethosuximide, } \\
\text { hydroxychloro } \\
\text { ibuprofen, } \\
\text { lididcainen(2), } \\
\text { meproanate, } \\
\text { valproic acid }\end{array}$ & & $\begin{array}{l}\text { acetamininophen (2), } \\
\text { cyanemazine (2), } \\
\text { nordiazepam (2) }\end{array}$ & & & \\
\hline
\end{tabular}

Figure 3. Comparison of LC-MS, GC-MS and HPLC-DAD in 51 clinical serum samples analyzed using three general unknown screening techniques preceded by a common SPE procedure. Number of occurrences are noted in brackets. analytical techniques can be considered as universal, and combining at least two of them significantly broadens the panel of compounds identified in many samples. Another interesting finding is that some of the compounds identified by only one technique were actually detected (but not positively identified) by another one at least. For instance, simvastatine, which belongs to the class of statine drugs against hypercholesterolemia, could only be positively identified by LC-MS because its UV and EI spectra were not specific enough to ascertain which compound it was in the statine class. Indeed, its $70 \mathrm{eV}$ EI mass spectrum does not show the protonated molecule, contrary to the reconstructed in-source CID spectrum. Simvastatine could be identified by its positive reconstructed MS that exhibits its molecular ion $(m / z$ 419.6), adducts of its molecular ion $(m / z 437.0)$, and of its dimer $(m / z$ 855.6) with ammonium, as well as several fragment ions. It could also be identified by its negative reconstructed spectrum, showing formate adducts of its molecular ion $(\mathrm{m} / \mathrm{z} 464.2)$ and its dimer $(\mathrm{m} / \mathrm{z}$ 882.8) (Figure 4). Noscapine could also be identified by LC-MS owing to the "enhance" function that significantly increased the signal-to-noise ratio of its reconstructed spectrum, whereas its UV and EI spectra could not be obtained with sufficient purity to reach good enough similarity with the spectra in the respective libraries.

Finally, $38.1 \%$ of all compounds could be identified simultaneously by the three techniques and $35.6 \%$ by two techniques, which is interesting in clinical toxicology and essential if the present technique is to be adapted to forensic toxicology, where, as in some countries, the positive identification of a suspected compound requires to be achieved using two different techniques.

Of note, the GC-MS GUS method used does not include any derivatization of the extracts, which would have probably increased the number of compounds detected by this technique, as abundantly demonstrated by Maurer et al. [1, 2, 20]. Nevertheless, we think that even the best derivatization procedure would not allow for the detection of all the compounds, such as chloralose or methotrexate for instance, that were only detected by LC-MS in the present study. The addition of deproteinated serum to the dry extract prior to LC-MS and not to the other two techniques probably did not play a significant role in the differences noted between 

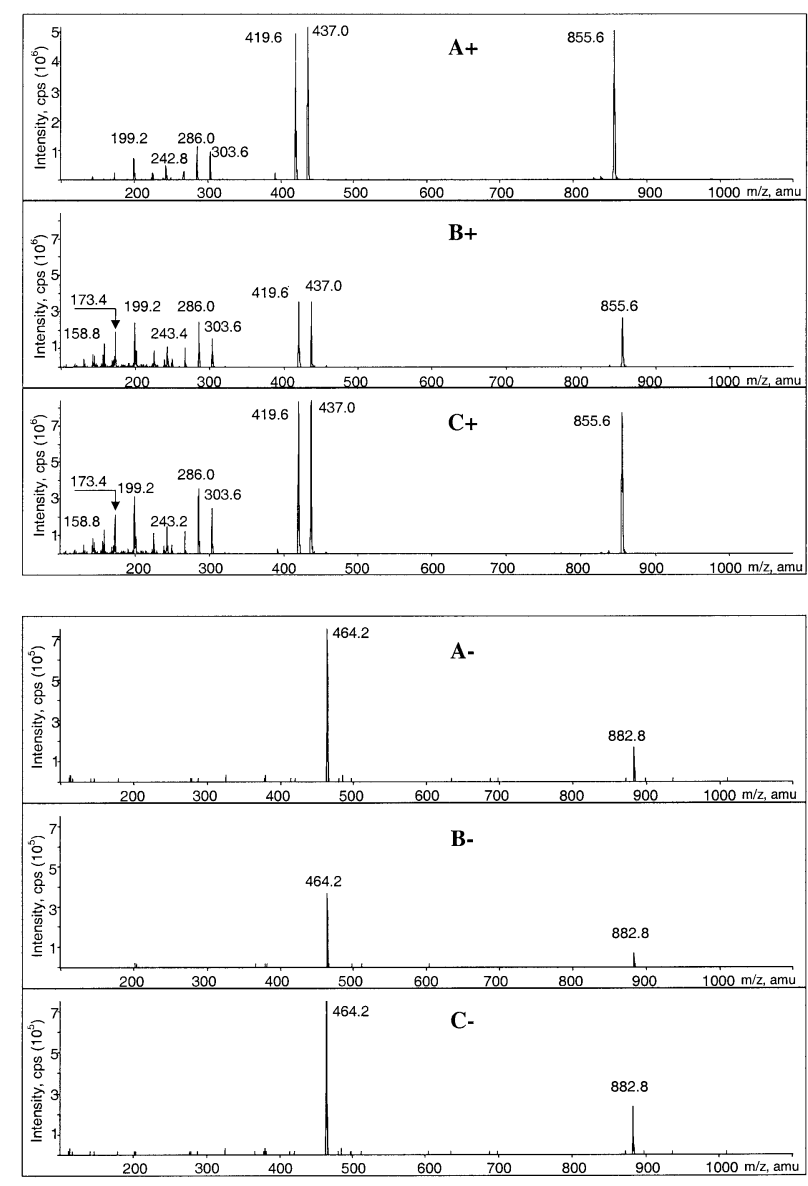

Figure 4. Building-up of simvastatine positive $(\mathrm{C}+)$ and negative reconstructed spectrum $(\mathrm{C}-)$ obtained by adding raw spectra acquired at fragmentation voltages $\pm 20 \mathrm{~V}(\mathrm{~A}+$ or $\mathrm{A}-$ ) and $\pm 80 \mathrm{~V}$ $(\mathrm{B}+$ or $\mathrm{B}-)$, respectively.

these techniques in the present study as we checked that even the most hydrophilic compounds such as chloralose and methotrexate were present in the dry extract. However, this additional step could be useful for other compounds and should not be considered as a bias in the present study, because it is only possible with LC-MS and is one of the advantages inherent to this technique. The aim was to compare complete, routine analytical procedures using as many common steps as possible but not to handicap any one of these by standardizing too many of these steps.

The comparison of LC-MS, GC-MS and HPLC-DAD GUS procedures presented herein is still preliminary, as 51 serum extracts cannot be representative of the activity of a clinical toxicology lab. However, these results suggest that the present comprehensive LC-ES-MS GUS technique is efficient (detection of $75 \%$ of all compounds) and complementary to GC-MS (percentage of compounds detected increased by $24.9 \%$ ) and HPLCDAD (percentage increased by $20.2 \%$ ). In our lab, the three analytical techniques are now employed simultaneously in routine work.

\section{Conclusion}

In-source CID has been used by several teams using different ionization and fragmentation conditions [14, 17]. To the best of our knowledge, they used two or three different fragmentation voltages and built different libraries corresponding to these fragmentation conditions. The originality of the procedure developed in our laboratory is the use of "reconstructed" and much more informative spectra obtained by adding a pair of spectra, one without and one with fragment ions, in both the positive and the negative modes $[8,9]$.

On the basis of this previously developed LC-ES-MS general unknown screening procedure, improvements were introduced into the present study, one of which is the reduction of total chromatographic time to $30 \mathrm{~min}$, which is an obvious advantage for clinical toxicology which requires accurate and fast information, with preserved resolution and peak width thus allowing automatic peak detection, integration, and compound identification. The solid-phase extraction method based on a mixed-mode support developed for LC-MS was shown to be as efficient as those routinely used in our laboratory for GC-MS and HPLC-DAD. Moreover, it requires a limited sample volume $(1 \mathrm{~mL})$, a single cartridge for the three techniques, and substantially shortens the total analytical time. A comparative study using clinical serum samples suggested that this comprehensive LC-MS GUS procedure was efficient enough to be used routinely and was complementary to GC-MS and HPLC-DAD, making the combination of these three techniques a global GUS strategy able to detect the widest range of therapeutic drugs and toxic compounds.

However, the lack of inter-instrument robustness of LC-MS as a GUS technique still limits its widespread use. Though it is possible to standardize fragmentation intensity on a given instrument and on instruments with identical ionization sources by using a reference compound (e.g., glafenin in the present study), it was recently shown that it was not possible to reproduce the same fragmentation intensity for all compounds using different types of instruments, i.e., electrospray-type sources with different configuration/geometry [21, 22]. It suggests that different mass spectral libraries should be built for the different types of ionization sources. However, the differences found only concerned the relative intensity of ions in the mass spectra, not their nature. Moreover, in all instances, the molecular or pseudomolecular ions and several fragments were present in the mass spectra. So, as our procedure attributes only small weight [9] to relative intensity, the apparent lack of robustness between different brands of instruments might not be insurmountable and requires further studies. 


\section{Acknowledgments}

The authors thank M. Jean-Louis Dupuy for excellent technical assistance and Applied Biosystem-Sciex for software development in relation with the present study.

\section{References}

1. Pfleger, K.; Maurer, H. H.; Weber, A. Mass Spectral and GC-Data of Drugs, Poisons, Pesticides, Polluants, and Their Metabolites; 2nd ed. VCH: Weinheim: New York, Basel, Cambridge, 1992.

2. Pfleger, K.; Maurer, H. H.; Weber, A. Mass Spectral and GC-Data of Drugs, Poisons, Pesticides, Pollutants, and Their Metabolites; 3rd ed. VCH: Weinheim: New York, Basel, Cambridge, 2000.

3. Pragst, F.; Herzler, M.; Herre, S.; Erxleben, B. T.; Rothe, M. UV-Spectra of Toxic Compounds. Verlag Dr. Dieter Helm: Heppenheim, Germany, 2001.

4. Maier, R. D.; Bogusz, M. Identification Power of a Standardized HPLC-DAD System for Systematic Toxicological Analysis. J. Anal. Toxicol. 1995, 19, 79-83.

5. Köppel, J.; Tenczer, J. Scope and Limitations of a General Unknown Screening by Gas Chromatography-Mass Spectrometry in Acute Poisoning. J. Am. Soc. Mass Spectrom. 1995, 6, 995-1003.

6. Marquet, P. Is LC-MS Suitable for a Comprehensive Screening of Drugs and Poisons in Clinical Toxicology? Ther. Drug Monit. 2002, 24, 125-133.

7. Marquet, P.; Dupuy, J. L.; Lachâtre, G. Development of a General Unknown Screening Procedure Using Liquid Chromatography-Ionspray-Mass Spectrometry. Proceedings of the ASMS Conference; Orlando, FL, June, 1998.

8. Marquet, P.; Venisse, N.; Lacassie, E.; Lachâtre, G. In-Source CID Mass Spectral Libraries for the "General Unknown" Screening of Drugs and Toxicants. Analysis 2000, 28, 41-50.

9. Venisse, N.; Marquet, P.; Duchoslav, E.; Dupuy, J. L.; Lachâtre, G. A General Unknown Screening Procedure for Drugs and Toxic Compounds in Serum Using Liquid ChromatographyElectrospray-Single Quadrupole Mass Spectrometry. J. Anal. Toxicol. , in press.

10. Marquet, P. Progress of Liquid Chromatography-Mass Spectrometry in Clinical and Forensic Toxicology. Ther. Drug Monit. 2002, 24, 255-276.
11. Spratt, E.; Vallaro, G. M. LC/MS with a Particule Beam Interface in Forensic Toxicology. Clin. Lab. Med. 1998, 18, 651-663.

12. Lips, A. G. A. M.; Lameijer, W.; Fokkens, R. H.; Nibbering, N. M. M. Methodology for the Development of a Drug Library Based Upon Collision-Induced Fragmentation for the Identification of Toxicologically Relevant Drugs in Plasma Samples. J. Chromatogr. B 2001, 759, 191-207.

13. Rittner, M.; Pragst, F.; Neumann, J. Screening Method for Seventy Psychoactive Drugs or Drug Metabolites in Serum Based on High-Performance Liquid Chromatography-Electrospray Ionization Mass Spectrometry. J. Anal. Toxicol. 2001, 25, 115-124.

14. Gergov, M.; Robson, J. N.; Duchoslav, E.; Ojanperä, I. Automated Liquid Chromatographic/Tandem Mass Spectrometric Method for Screening $\beta$-Blocking Drugs in Urine. J. Mass Spectrom. 2000, 35, 912-918.

15. Weinmann, W.; Lehmann, N.; Müller, C.; Wiedemann, A.; Svoboda, M. Identification of Lorazepam and Sildenafil as Examples for the Application of LC/Ionspray-MS and MS-MS with Mass Spectra Library Searching in Forensic Toxicology. Forensic Sci. Int. 2000, 113, 339-344.

16. Müller, C.; Vogt, S.; Goerke, R.; Kordon, A.; Weinmann, W. Identification of Selected Psychopharmaceuticals and Their Metabolites in Hair by LC/ESI-CID/MS and LC/MS/MS. Forensic Sci. Int. 2000, 113, 415-421.

17. Weinmann, W.; Wiedemann, A.; Eppinger, B.; Renz, M.; Svoboda, M. Screening for Drugs in Serum by Electrospray Ionization/Collision-Induced Dissociation and Library Searching. J. Am. Soc. Mass Spectrom. 1999, 10, 1028-1037.

18. The Wiley Registry of Mass Spectral Data; 7th ed. John Wiley and Sons, Inc.: New York, 2000.

19. Flanagan, R. J. Guidelines for the Interpretation of Analytical Toxicology Results and Unit of Measurement Conversion Factors. Ann. Clin. Biochem. 1998, 35, 261-267.

20. Maurer, H. H.; Arlt, J. W.; Kraemer, T.; Schmitt, C. J.; Weber, A. A. Analytical Development for Low Molecular Weight Xenobiotic Compounds. Arch. Toxicol. Suppl. 1997, 19, 189197.

21. Rivier, L. Robustness Evaluation for Automatic Identification of General Unknown by Reference ESI Mass Spectra Comparison in LC-MS Toxicological Screening. Proceedings of the 37th TIAFT Meeting; Prague, Czech Republic, August 2001, p 71.

22. Weinmann, W.; Stoertzel, M.; Vogt, S.; Wendt, J. Tune Compounds for Electrospray Ionization/In-Source Collision-Induced Dissociation with Mass Spectral Library Searching. J. Chromatogr. A 2001, 926, 199-209. 